\title{
Epidemiological Study on Human, Cattle and Rodent Leptospirosis in South Gujarat Region of India
}

\author{
Tanvi Harivadanbhai Panwala
}

Microbiology department, Government Medical College, Surat, Gujarat. India

\begin{abstract}
Background: Surat district and neighbouring districts like Valsad, Navsari in South Gujarat region are considered as an endemic area for leptosprirosis. Types of leptospira serovars are depend on geographical area so it was important to find serovars which are predominant in humans, cattle and environment (soil, water) of this area. So aim of the study was to establish the transmission cycle of leprospirosis in this area by Isolation techniques and serology.

Material and Methods: 207 human, 92 rodent and 258 animal blood samples were subjected to PCR, MAT test and culture in EMJH media. In addition, 550 animal urine, 7 rodent urine, 19 animal kidney and 571 rodent kidney were also tested by PCR.

Results: Out of total 207 suspected cases, 161 samples were positive by MAT and 94(45\%) positive by Real time PCR. 51(24\%) samples were positive by MAT and PCR both tests. In cattle and rodent, 65 and 9 serum samples were positive by MAT test for leptospirosis. Predominant serovars observed in human cases, cattle and rodents were L. Autumnalis, L. Canicola, L. Pomona and L. Icterohaemorrahgiae.

Conclusion: The current study reveals the presence of common leptospiral serovars, Autumnalis and Pomona infecting man, animals, and rodents, by serology and isolation. Hence this study reiterates the need for a strong and highly detailed control program for leptospirosis in this region, which should begin from the rodents and encompass the domestic animals as well.
\end{abstract}

Keywords: Leptospirosis; MAT (Microscopic Agglutination Test); PCR (Polymerize Chain Reaction)

\section{Introduction}

Leptospirosis is common bacterial zoonosis worldwide, caused by spirochetes of genus Leptospira. Wild rodents serve as a natural reservoirs of infection, human and few others domesticated animals are accidental hosts in the transmission cycle of leptospirosis ${ }^{[1,2]}$ which can lead to abortion, stillbirth, infertility, mastitis, weak progeny and decreased milk production in them. ${ }^{[3,4]}$ The key feature in the transmission of Leptospirosis between animals, and between animals and man, is infection of renal tubules and excretion of infectious leptospires in the urine of carrier animals. Urine shed from carrier animal can result in direct transmission of the infection via contamination of mucous membranes of another animal, or in indirect transmission via contamination of the environment. The scenario of leptospiral infection is different in developed and developing countries. In developed countries, infection is increasingly being associated with outdoor recreational exposure and international travel. In rural areas of developing countries, transmission is usually associated with farming and livestock. In urban areas, infection is associated with overcrowding, poor hygiene standards, inadequate sanitation and poverty, all of which typically takes place in urban slums of developing countries. ${ }^{[5]}$
Suitability of environmental condition for survival of leptospires appears to be critical factor in maintaining the infection. Factors like tropical climates with heavy rainfall, stagnant waters, poor level of sanitation, occupational or recreational exposure and close proximity of mammalian reservoir to human population are associated with endemic leptospirosis ${ }^{[6,7]}$ Increased temperature may lengthen the survival rate of leptospires in the environment and can result in expansion of these reservoir species into higher elevation and latitudes. Hence, these all global climatic changes are contributing to leptospirosis as an emerging disease. ${ }^{[8]}$

A basic knowledge of serovars and their maintenance hosts is required to understand the epidemiology of leptospirosis in a region. Though there is distinct variation in maintenance hosts and the serovars they carry can occur throughout the world. ${ }^{[9]}$ Generally dairy cattle have a role as a natural host of serovars Hardjo, Pomona and Gripphotyphosa, while pigs may harbor Pomona, Tarassovi, and Bratislava. Sheep may harbor serovars Hardjo and Pomona, and dogs may harbor serovar Canicola. ${ }^{[10]}$ Diagnosis of leptospirosis in animals is done by three different methods which include the isolation from samples, detection of leptospiral DNA by real time polymerase chain reaction and detection 
of anti- leptospiral antibodies. Isolation by culture is very time consuming, laborious and depends upon the presence of live leptospira in sample, so PCR and serology are the only method used for diagnosis. The detection of antileptospiral antibodies can be done with MAT (Microscopic Agglutination Test) and ELISA (enzyme linked immunosorbent assay). ${ }^{[11]}$ MAT test can be used qualitatively and quantitatively to detect infecting serovars as well as give the titer of individual serovars. Furthermore the sensitivity and specificity of MAT in reported study were $91.94 \%$ and $73.77 \%$ respectively. ${ }^{[12]}$ It is therefore important to have knowledge of the serovars present and their reservoir host.

Surat district and area around Surat district including neighbouring districts like Valsad and Navsari are considered as endemic area of leptosprirosis. Reporting of cases coincide with the rainy season as well as amount of rainfall. Case fatality due to leptospirosis in Surat district remains below 15\% except in 1996 and 2006 when it was $22 \%$ and $28 \%$ respectively. As the leptospirosis is common in this area, present study was designed to establish the transmission cycle of leprospirosis. Types of serovars are depending on geographical area so it is important to find serovars which are predominant in humans, animals and environment (soil, water) of this area. Understanding serovar host dynamics and transmission cycle may help in better designing of preventive and treatment strategies so that mortality and complications of this infection can be decreased.

\section{Materials and Methods}

A retrospective study was conducted during the period of July 2008 to November 2008.207 samples were collected from suspected leptospirosis patients admitted in New Civil Hospital, Surat, South Gujarat. Serum samples were subjected MAT and PCR. The informed consent was taken from all suspected leptospirosis patients. Clinical suspicion of acute Leptospirosis was defined as fever and/or myalgia, tender liver, jaundice, acute renal failure, bleeding tendency, meningism and radiological lung infiltrates which accounted in the first week of fever. Patients confirmed for other diseases like hepatitis, malaria, dengue etc. were excluded from the study. Cattle $(n=258)$ and rodents $(n=92)$ serum samples were received at Microbiology laboratory in cold chain from different endemic areas of south Gujarat region and tested by Microscopic Agglutination Test and PCR for leptospirosis. The cattle included in present study were from various sources representing the diverse livestock production system e.g. rural subsistence, periurban, semi commercial and organized commercial dairy farms, where human leptospirosis cases were known to occur. 550 cattle urine and 7 rodents' urine samples were also received to the laboratory and were subjected to PCR. In addition, 19 cattle kidney and 571 rat kidney samples were screened by PCR.

Microscopic Agglutination Tests (MAT): The MAT test was performed using standard procedure. ${ }^{[13]}$ Serogroups included in the antigen panel L. australis, L. autumnalis, L. grippotyphosa, L. canicola, L. hebdomadis, L. pomona, L. semeranga (patoc), L. pyrogen (Pyrogen) and $L$. icterohaemorrhagiea. All the strains were obtained from the National Leptospirosis Reference Centre, Regional Medical Research Centre (World Health Organization collaborating centre for diagnosis in leptospirosis, ICMR) in Port Blair, Andaman and Nicobar islands. The cultures used as antigens should be checked by MAT against homologous antisera frequently for quality control. These serovars were maintained in $0.1 \%$ semisolid EMJH agar by using Leptospira medium base supplemented with $10 \%$ enrichment (Diffco, USA) at $28-30^{\circ} \mathrm{C}$ in screwcapped test tubes.

Preparation of antigens: A $0.5 \mathrm{ml}$ of each representative strain from the panel of 12serovars was inoculated into $10 \mathrm{ml}$ of liquid EMJH medium. A loopful of culture was checked under dark field microscopy to confirm the absence of contamination or clumps and presence of viable leptospires. Incubation was done at $30^{\circ} \mathrm{C}$ for five to seven days. A density of approximately $2-3 \times 10^{8}$ leptospira $/ \mathrm{ml}$ of media was used as an antigen.

Procedure: Doubling dilutions from 1 in 10 to 1 in 640were prepared by using phosphate buffer saline as a diluents. $50 u$ of the specific serovar was added to all the wells. One of the wells included only the antigen without addition of antibody and served as the antigen control. The final dilutions after adding the antigen were from 1 in 20 to 1 in 1280 . The plates were covered with aluminum foil and incubated at $37{ }^{\circ} \mathrm{C}$ for $2 \mathrm{~h}$. The highest serum dilution showing approximately $50 \%$ agglutinated leptospires or a reduction in the number of leptospiral cells as compared to the antigen control was taken as end point titer. A titer of 1 in 80 or more was considered positive.

Isolation Procedure of Leptospira Spp: Whole blood samples collected upon admission of patients were cultured in Ellinghausen-McCullough-Johnson-Harris liquid medium supplemented with enrichment medium and 5-fluorouracil $(200 \mu \mathrm{g} / \mathrm{ml})$ and incubated aerobically at $28^{\circ}-30^{\circ} \mathrm{C}$. A drop from each culture medium was examined weekly, for 3 months by dark field microscopy. In case of contamination, cultures were filtered through 0.22 um pores to remove contaminants. ${ }^{[14]}$ 
Serogrouping: Serological characterization of clinical isolates was performed at the National Reference Center ICMR, Portblair, India for Leptospira. A Microscopic agglutination test (MAT) was performed to determine the serogroup of Leptospira isolates using rabbit antisera against reference serovars representing a standard battery of 24 serogroups. High rates of agglutination of the serum with one particular antigen were used to identify the presumptive serogroup of the infecting bacterium. ${ }^{[15]}$

Real Time PCR Assay: Total DNA from cattle serum $(200 \mu \mathrm{l})$ was prepared using QIAamp DNA Mini Kits (QIAGEN, USA) according to the manufacturer's instructions. The primers and probes were designed from alignments of available Leptospira spp. LipL41 sequences obtained from the GenBank nucleotide sequence database. The program used was Primer Express ${ }^{\mathrm{TM}}$ (Applied Biosystems, USA). For real time PCR, $5 \mu$ of DNA was added to the $45 \mu$ lTaqMan Universal PCR Master Mix (Applied Biosystems, USA) in final concentrations of 3 $\mathrm{pmol} / \mu \mathrm{l}$ of each primer and $2 \mathrm{pmol} / \mu \mathrm{l}$ of the FAM-TAMRA labelled probe. A negative control without added template in the above reaction mixture was used as a control to detect the presence of contaminating DNA. Amplification and fluorescence detection was conducted in an ABI Prism 7300 sequence detector (Applied Biosystems, USA) with a program of 40 cycles, each cycle consisting of $95^{\circ} \mathrm{C}$ for 15 seconds and $60^{\circ} \mathrm{C}$ for one minute as per the manufacturer's instructions.

\section{Result}

Total 207 human cases of suspected leptospirosis were referred to New Civil Hospital, Surat for the treatment. Of 207 cases; 108 (52\%) were from Surat district and 99
(48\%) were from neighboring Valsad district. Of the 207, $108(52 \%)$ of patients were of middle age group (20-39 year), $79(38 \%)$ were having age above 40 years and 20 $(10 \%)$ were below 19 years. Majority of cases were males as compared to females ( $82 \%$ versus $18 \%$ ). Out of total 207 suspected cases, $161(77.7 \%)$ samples were positive by MAT and 94(45\%) positive by Real time PCR. 51(24\%) samples were positive by MAT and PCR both tests.

Different samples from cattle [urine $(\mathrm{n}=550)$, serum $(n=258)$, kidney $(n=19)]$ and rodent [urine $(n=7)$, serum $(\mathrm{n}=92)$, kidney $(\mathrm{n}=571)$ ] were also received at Microbiology department. In cattle, 27 urine samples, 31 serum and 2 kidney samples were positive by PCR for leptospirosis. In rodent, 36 kidney samples were positive by PCR for leptospirosis and all urine and serum samples were negative. In cattle, out of 258 serum samples, 65 $(25.1 \%, 95 \%$ CI $20.2 \%$ to $30.8 \%)$ were positive by MAT test for leptospirosis and out of 92 rodent serum samples 9 (33.3\%, 95\% CI $18.6 \%$ to $52.1 \%$ ) were positive by MAT test for leptospirosis. MAT and PCR results of different samples from cattle and rodent had also shown in table.1.

Predominant serovars observed in human cases, cattle and rodents by doing MAT test are shown in table 2. Serovars common to all three species (Human, Cattle and rodent) were L. autumnalis, L. Canicola, L. Pomona and L. Icterohaemorrhagiea. Three other species L. Australis, L. Hebdomadis and L. Pyrogen were common only in human and cattle. 3 Leptospira species were isolated from three human patients in EMJH media with $10 \%$ rabbit sera. The results of serotyping from National Leptospirosis Reference Centre, Port Blair, suggested that two of the isolates belonged to serogroup Autumnalis and one was from Pomona.

Table 1: shows PCR and MAT results of different samples from Cattle and Rodents.

\begin{tabular}{|l|c|c|c|c|c|c|}
\hline Test & $\begin{array}{c}\text { Cattle urine } \\
(\mathbf{N}=\mathbf{5 5 0})\end{array}$ & $\begin{array}{c}\text { Cattle serum } \\
(\mathbf{N}=\mathbf{2 5 8})\end{array}$ & $\begin{array}{c}\text { Cattle kidney } \\
(\mathbf{N}=\mathbf{1 9})\end{array}$ & $\begin{array}{c}\text { Rodent urine } \\
\mathbf{( N = 7 )}\end{array}$ & $\begin{array}{c}\text { Rodent Serum } \\
(\mathbf{N}=\mathbf{9 2})\end{array}$ & $\begin{array}{c}\text { Rodent Kidney } \\
(\mathbf{N}=\mathbf{5 7 1})\end{array}$ \\
\hline PCR Positive & 27 & 31 & 2 & 0 & 0 & 36 \\
\hline PCR Negative & 523 & 227 & 17 & 7 & 92 & 535 \\
\hline MAT positive & -- & 65 & -- & -- & 9 & -- \\
\hline MAT negative & -- & 193 & -- & -- & 83 & -- \\
\hline
\end{tabular}

Table 2: Predominant serovars from serum of human, cattle and rodents by MAT test.

\begin{tabular}{|l|c|c|c|}
\hline Serovars & Human $(\mathbf{n}=\mathbf{1 6 1})$ & Cattle $(\mathbf{n}=\mathbf{6 5})$ & Rodent $(\mathbf{n = 9})$ \\
\hline L. Pyrogen & $32(20)$ & $1(1)$ & 0 \\
\hline L. Australis & $31(19)$ & $2(3)$ & 0 \\
\hline L. Autumnalis & $73(45)$ & $21(34)$ & $6(66)$ \\
\hline
\end{tabular}




\begin{tabular}{|l|c|c|c|}
\hline Serovars & Human $(\mathbf{n = 1 6 1 )}$ & Cattle $(\mathbf{n}=\mathbf{6 5})$ & Rodent $(\mathbf{n = 9})$ \\
\hline L. Gripphotyphosa & $2(1)$ & 0 & 0 \\
\hline L. Canicola & $15(9)$ & $12(18)$ & $1(11)$ \\
\hline L. Pomona & $3(2)$ & $7(11)$ & $1(11)$ \\
\hline L. Icterohaemorrahgiae & $4(2)$ & $13(20)$ & $1(11)$ \\
\hline L. Hebdomadis & $1(0.6)$ & $9(14)$ & 0 \\
\hline
\end{tabular}

(Value in parenthesis is percentages)

\section{Discussion}

The present study was carried out to detect the presence of common serovars of leptospira infecting the cattle and human beings in South Gujarat region by MAT and culture methods and also to understand transmission cycle of leptospirosis in this geographical area. Heavy rainfall and flooding increase the risk of leptospirosis by bringing bacteria and their animal hosts into closer contact with humans. Numerous outbreaks of leptospirosis have been reported following extreme weather events around the world, in geographically diverse areas including India, Laos, Indonesia, Italy, Brazil, Guyana Nicaragua, Puerto Rico, the USA, New Caledonia and Australia. ${ }^{[16]}$

Surat district and area around Surat district including neighbouring districts like Valsad and Navsari in South Gujarat are considered as endemic areas for leptosprirosis. Each year the area from where the cases come is expanding. First case was reported in 1994 and peak was observed in 1998 with fluctuations thereafter. Reporting of cases coincide with the rainy season (Between June to October) as well as amount of rainfall (heavy rainfall more cases). Case fatality due to leptospirosis in Surat district remains below $15 \%$ except in 1996 and 2006 when it was $22 \%$ and $28 \%$ respectively. Majority of cases came from laborers working in sugar cane and rice field. As transmission cycle varies with the host, agent and environment so it was necessary to explore transmission cycle in this area which was yet to be explored as done in the case of other areas of India and world. ${ }^{[6,17,18,19]}$

In present study, 36 rodent kidney samples were PCR positive and in 9 rodent serum samples were showing agglutinating antibodies against different serovars of leptospira in MAT test. Rodents are susceptible to acute infection only in the early days of their life. Later, the immune system develops, and surviving ones become resistant to further infection. ${ }^{[20]}$ This could be a probable reason for the low levels of antibodies detected in rodents. As the leptospires get lodged in the renal tubules of the rodents, rodent urine becomes a source of leptospiral infection in grazing animals like cattle, which in turn contribute to infection in human beings. ${ }^{[21]}$ Leptospira could be isolated from three human patients in EMJH media with $10 \%$ rabbit sera. The inability to isolate Leptospira from other infected human beings could be attributed to administration of antibiotics by local practitioners before the patients were referred to the hospitals. ${ }^{[22]}$ The results of serotyping from National Leptospirosis Reference Centre, Port Blair, suggested that two of the isolates belonged to serogroup L.Autumnalis and one was from L.Pomona. The MAT conducted on human, cattle and rodent's sera also revealed that predominant serovars common to all three species were L. autumnalis, L. Canicola, L. Pomona and L. Icterohaemorrhagiea. L.Autumnalis and L.Pomona as the predominant serovars infecting man, cattle and rodents. These strains from domestic and peridomestic animals play a major role in the epidemiology of human leptospirosis. Similar observation was also found in other studies suggested the antileptospiral antibodies belonging to serovars L.Autumnalis. ${ }^{[23,24,25]}$ As this serovar had been included as an antigen for MAT in this study, the possibility of L.Autumnalis being the predominant serovar in this region. MAT should ideally be done on paired sera samples, for detection of a fourfold rise in the antibody titer. Since agglutinins to MAT tend to remain in the body for a prolonged period of time following infection, detectable MAT titers may be present even in healthy animals and man. But in an acute infection, MAT titers develop very late in the body usually by the second to fourth week of infection. These two factors may account for the false Positive and the false negative results by MAT. ${ }^{[24]}$ In present study, the cutoff titer for MAT in humans and cattle were kept at 1: 80 dilutions as per results cited by various authors. ${ }^{[13,26,27]}$

The MAT has many disadvantages which indicate the need for an alternative test for routine diagnosis of leptospirosis. One major problem with the MAT is its use of live organisms as antigens. This requires the continuous culture and handling of these hazardous bacteria in laboratories and the subjective assessment of results can 
also make quality assurance of the MAT difficult. Another problem associated with the MAT is that it only detects agglutinating antibodies and non-agglutinating antibodies may go undetected.

\section{Conclusion}

Control measures for leptospirosis should begin from rodents, which are the main reservoir hosts of Leptospira, and domestic animals, which are the carrier hosts of the infection. The current study reveals the presence of common leptospiral serovars L.Autumnalis and L.Pomona infecting man, cattle and rodents, by serology and isolation. Hence this study reiterates the need for a strong and highly detailed control program for leptospirosis in this region, which should begin from the rodents and encompass the domestic animals as well.

\section{Acknowledgements}

We acknowledge the extended support from ICMR; port Blair for providing leptospira strains and Government of Gujarat, Health for supporting us to conduct the study.

\section{Reference}

1. Adler B, de la Peña Moctezuma A. Leptospira and leptospirosis. Vet Microbiol2010; 140: 287-296.

2. Cinco M. New insights into the pathogenicity of leptospires: evasion of host defences. New Microbiol2010; 33: 283-292.

3. Bey RF., Johnson RC. Current status of leptospiral vaccines .Prog.vet. Microbiol. Immunol 1986; 2:175-197.

4. Songer JG., Chilelli CJ., Marshall M.M., Noon T.H., Meyer R., 1983. Serological survey for leptospirosis in Arizona beef cattle in 1981. Am. J. vet. Res., 44: 1763-1764.

5. Lau C, Smythe L, Weinstein P. Leptospirosis — an emerging disease in travellers. Travel Med Infect Dis 2010; 8: 33-39.

6. Sharma S, Vijayachari P, Sugunan AP, Natarajaseenivasan K, Sehgal SC. Seroprevalence of leptospirosis among highrisk population of andaman islands, India. Am J Trop Med Hyg2006; 74: 278-283.

7. Guerra MA. Leptospirosis: Public health perspectives. Biologicals : journal of the International Association of Biological Standardization. 2013;41(5):295297. doi:10.1016/j.biologicals.2013.06.010.

8. Chen I-C, Hill JK, Ohlemuller R, Roy DB, Thomas CD. Rapid range shifts of species associated with high levels of climate warming. Science. 2011; 333:1024-6. [PubMed: 21852500 .

9. Levett PN. Leptospirosis: a forgotten zoonosis? ClinApplImmunol Rev 2004; 4: 435-448.

10. Bolin C. Leptospirosis, In: Brown C, Bolin C, eds. Emerging diseases of animals. Washington, DC: ASM Press, 2000; 185-200.
11. Brandão AP, Camargo ED, da Silva ED, Silva MV, Abrão RV. Macroscopic agglutination test for rapid diagnosis of human leptospirosis. J ClinMicrobiol 1998; 36: 3138-3142.

12. Dassanayake DLB, Wimalaratna H, Agampodi SB, Liyanapathrirana VC, Piyarathna TACL, Goonapienuwala BL et al. Evaluation of surveillance case definition in the diagnosis of leptospirosis, using the microscopic agglutination test: a validation study. BMC Infect Dis 2009; 9: 48.

13. Vijayachari P, Suganan AP, Sehgal SC. Role of microscopic agglutination test (MAT) as a diagnostic tool during acute stage of leptospirosisin low and high endemic areas. Indian J Med Res 2001;114:99-106.

14. Goris MGA, Leeflang MMG, Loden M, Wagenaar JFP, Klatser PR et al. Prospective Evaluation of Three Rapid Diagnostic Tests for diagnosis of Human Leptospirosis. PLoS Negl Trop Dis 2013; 7(7): e2290.

15. Dikken H, Kmety E. Serological typing methods of leptospires. Methods in Microbiology, London: Academic Press eds. Bergan T, Norris JR. 1978;Pp 259-307.

16. Lau CL, Smythe LD, Craig SB, Weinstein P. Climate change,flooding, urbanisation and leptospirosis: fuelling the fire. Trans RSoc Trop Med Hyg 2010; 104: 631-638.

17. Brown PD, McKenzie M, Pinnock M, McGrowder D. Environmental risk factors associated with leptospirosis among butchers and their associates in Jamaica. The international journal of occupational and environmental medicine 2011 Jan;2(1):47-57. PubMed PMID: 23022818. Epub 2011/01/01. eng.

18. Chusri S, Sritrairatchai S, Hortiwahul T, Charoenmak B, Silpapojakul K. Leptospirosis among river water rafters in Satoon, southern Thailand. Journal of the Medical Association of Thailand $=$ Chotmaihet thangphaet. 2012 Jul;95(7):874-7. PubMed PMID: 22919980. Epub 2012/08/28. eng.

19. Lau CL, Skelly C, Smythe LD, Craig SB, Weinstein P. Emergence of new leptospiral serovars in American Samoa - ascertainment or ecological change? BMC infectious diseases. 2012;12:19. PubMed PMID: 22273116. Pubmed Central PMCID: PMC3305655. Epub 2012/01/26. eng.

20. Faine S. Guidelines for the control of leptospirosis. World Health Organisation, offset publication No.67, Geneva, Switzerland. 1982. P.171.

21. Soman M., Jayaprakasan V., Mini M., Seroprevalence of Leptospirosis in Human beings and Animals in Central and North Kerala. Journal of Agriculture and Veterinary Science 2014; 7: 38-41.

22. Bharadwaj R., Bal AM., Joshi SA., Kagal A., Pol S.S, et al. An outbreak of leptospirosis in Mumbai, India. Jpn. J. Infect. Dis 2002;55:194-196. 
23. Priya CG, Hoogendijk KT, Berg M, Rathinam SR, Ahmed A, Muthukkaruppan VR, et al. Field rats form a measure infection source of leptospirosis in and around Madurai, India. J Postgrad Med 2007;53:236-40. Back to cited text no. 9 [PUBMED]

24. Natarajaseenivasan K, Vedhagiri K, Sivabalan V, Prabagaran SG, Sukumar S, Artiushin SC, et al. Seroprevalence of Leptospira borgpetersenii serovar javanica infection among dairy cattle, rats and humans in the Cauvery river valley of southern India. Southeast Asian J Trop Med Public Health 2011; 42:679-86.
25. Kuriakose M, Paul R, Joseph MR, Sugathan S, Sudha TN. Leptospirosis in a midland rural area of Kerala State. Indian J Med Res 2008; 128:307-12.

26. Arumugam, G, Jacob, S.M, Anitha, D. and Rajappa, S.M. Occurrence of leptospirosis among suspected cases in Chennai, Tamil Nadu. Indian J. Pathol. Microbiol2011;54: 100-2.

27. Panwala, T., Mulla, S. and Patel, P. Seroprevalence of leptospirosis in South Gujarat region by evaluating the two rapid commercial diagnostic kits against the mat test for detection of antibodies to Leptospira interrogans. Natl.J. Community Med 2011; 2(1): 64-70.

*Corresponding author:

Tanvi Harivadanbhai Panwala, Microbiology department, Government Medical College, Surat, Gujarat. India

Email: drtanvi2006@yahoo.co.in

Date of Submission : 13.01.2017

Date of Acceptance : 27.06.2017

Financial or other Competing Interests: None.

Date of Publication : 25.10.2017 